\title{
Coronavirus disease 2019 (COVID-19): Team preparation and approach to tracheostomy
}

\section{Guidelines and Recommendations from Cleveland Clinic COVID-19 Tracheostomy Working Group}

Alejandro C. Bribriesco, MD, ${ }^{\mathrm{a}}$ Monisha Sudarshan, MD, MPH, ${ }^{\mathrm{a}}$ Colin T. Gillespie, MD, ${ }^{\mathrm{b}}$

Paul C. Bryson, MD, ${ }^{\mathrm{c}}$ Brandon Hopkins, MD,${ }^{\mathrm{c}}$ Donna Tanner, RRT-ACCS, ${ }^{\mathrm{d}}$ Siva Raja, MD, PhD, ${ }^{\mathrm{a}}$

Usman Ahmad, MD, ${ }^{a}$ Daniel P. Raymond, MD, ${ }^{a}$ and Sudish C. Murthy, MD, PhD, ${ }^{a}$ Cleveland, Ohio

\footnotetext{
From the ${ }^{\mathrm{a} D e p a r t m e n t}$ of Thoracic and Cardiovascular Surgery, Heart Vascular and Thoracic Institute; ${ }^{\mathrm{b}}$ Section of Interventional Pulmonology, Respiratory Institute; ${ }^{c}$ Department of Otolaryngology, Head and Neck Institute; and ${ }^{\mathrm{d}}$ Department of Intensive Care and Resuscitation, Anesthesia Institute, Cleveland Clinic, Cleveland, Ohio. Drs Bribriesco and Sudarshan contributed equally to this article.

Disclosures: Dr Raja is a consultant for Smiths Medical. All other authors reported no conflicts of interest.

The Journal policy requires editors and reviewers to disclose conflicts of interest and to decline handling or reviewing manuscripts for which they may have a conflict of interest. The editors and reviewers of this article have no conflicts of interest.

Received for publication Nov 19, 2020; accepted for publication Nov 19, 2020; available ahead of print Dec 7, 2020 .

Address for reprints: Alejandro C. Bribriesco, MD, Department of Thoracic and Cardiovascular Surgery, Cleveland Clinic, 9500 Euclid Ave/Mail Stop J4-1, Cleveland, OH 44195 (E-mail: bribria@ccf.org).

JTCVS Techniques 2021;6:183-7

2666-2507

Published by Elsevier Inc. on behalf of The American Association for Thoracic Surgery. This is an open access article under the CC BY-NC-ND license (http://creativecommons.org/licenses/by-nc-nd/4.0/).

https://doi.org/10.1016/j.xjtc.2020.11.023
}

Video clip is available online.

Tracheostomy has become a common surgical intervention performed on patients with severe coronavirus disease 2019 (COVID-19), as mechanical ventilation is required in $10 \%$ to $15 \%$ of patients. ${ }^{1}$ High risk of aerosolization during the intervention is a serious concern for personnel involved both during and after tracheostomy placement. We present

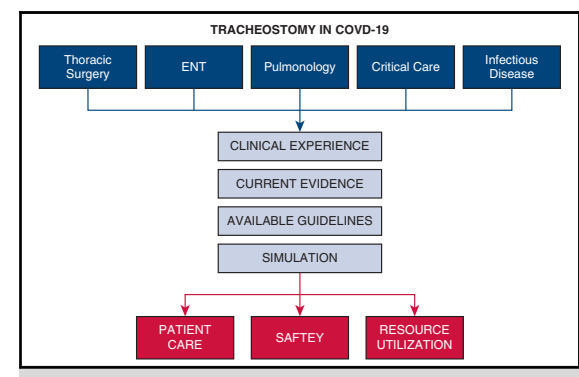

Multidisciplinary approach to devising a protocol for tracheostomy in COVID-19 patients.

CENTRAL MESSAGE

Tracheostomy in COVID-19

patients is a necessary but high

exposure risk procedure. A

multidisciplinary approach with

use of simulation is invaluable for

development of a safe and effi-

cient protocol.

See Commentaries on pages 188 and 190.

TABLE 1. Pros and cons consideration for tracheostomy in patients with COVID-19

\begin{tabular}{|c|c|c|c|}
\hline & Patient & Health care system & HCW \\
\hline Pros & $\begin{array}{l}\text { - Comfort } \\
\text { - Less sedation } \\
\text { - Time to speak } \\
\text { - Time to swallow } \\
\text { - Secretion management }\end{array}$ & $\begin{array}{l}\text { - Decreased vent days } \\
\text { - Decreased ICU days } \\
\text { - Less nursing care and sedation }\end{array}$ & $\begin{array}{l}\text { - Avoid reintubation HCW exposure } \\
\text { - Sealed system (avoiding use of CPAP, } \\
\text { high-flow nasal cannula) }\end{array}$ \\
\hline $\begin{array}{l}\text { Unknown } \\
\text { Benefit/Risk }\end{array}$ & $\begin{array}{l}\text { - PT/OT } \\
\text { - Prevent tracheal stenosis if } \\
\text { tracheostomy }<21 \mathrm{~d}\end{array}$ & $\begin{array}{l}\text { - Sedation medication } \\
\text { - Disposition out of acute } \\
\text { hospitalization }\end{array}$ & $\begin{array}{l}\text { - Virus exposure through tracheostomy to } \\
\mathrm{HCW} \text { on floor/rehab facility }\end{array}$ \\
\hline Cons & $\begin{array}{l}\text { - Derecruitment during procedure } \\
\text { - Possible bleeding } \\
\text { - Possible tracheostomy complications }\end{array}$ & $\begin{array}{l}\text { - Exposure risk to HCW with } \\
\text { difficult to replace specific skill set }\end{array}$ & $\begin{array}{l}\text { - HCW exposure during procedure } \\
\text { - Possible increased } \mathrm{HCW} \text { exposure during } \\
\text { tracheostomy maintenance/care }\end{array}$ \\
\hline
\end{tabular}

$\overline{H C W}$, Health care worker; $I C U$, intensive care unit; $C P A P$, continuous positive airway pressure; $P T / O T$, physical therapy/occupational therapy. 


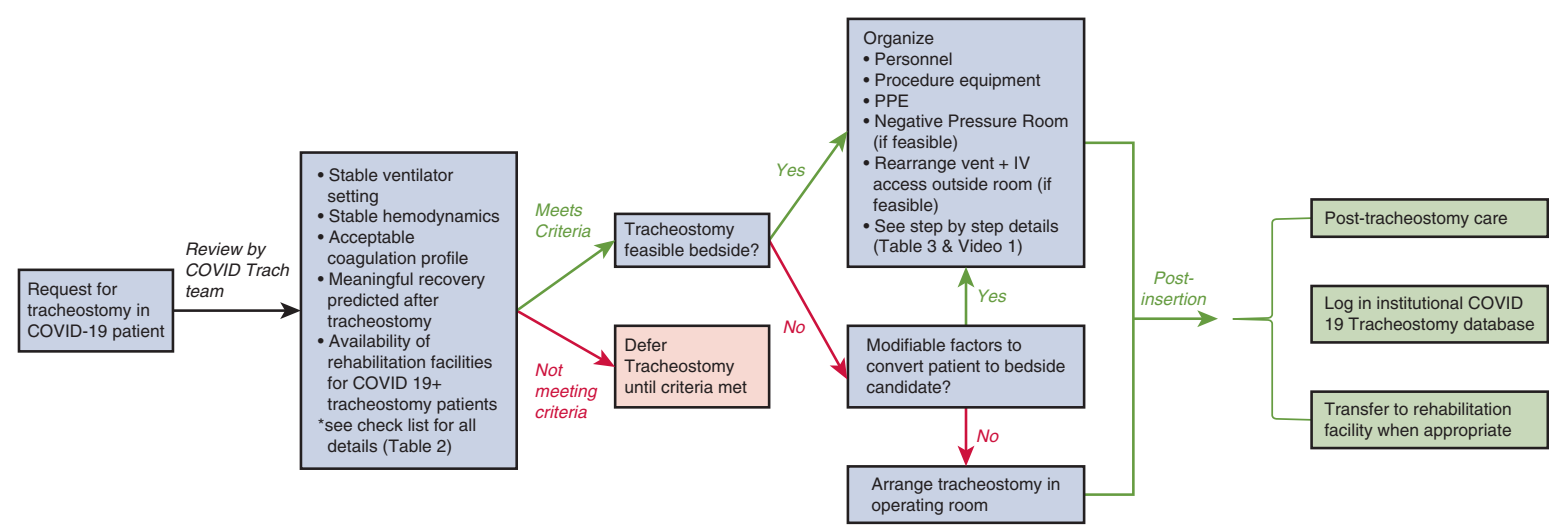

FIGURE 1. Approaching tracheostomy insertion in the patient with COVID-19. COVID-19, Coronavirus disease 2019; PPE, personal protective equipment.

our experience developing a multidisciplinary algorithm to tracheostomy for COVID-19 respiratory failure. We recognize that this process will vary based on institutional policy and will evolve with further data on transmission and respiratory consequences of COVID-19.

\section{THE ROLE AND BENEFITS OF}

\section{MULTIDISCIPLINARY TEAM AND SIMULATION}

As the COVID-19 crisis unfolded, virtual meetings were held to develop a unified institutional approach for tracheostomy with multidisciplinary stakeholders: Thoracic Surgery, Otolaryngology, Pulmonology, Critical Care, Anesthesiology, and Respiratory Therapy. Discussions centered on indications, contraindications, timeline to tracheostomy, and special procedural considerations (Table 1).
Next, we performed high-fidelity tracheostomy simulation in our laboratory to rehearse and fine-tune procedural details. including proper donning and doffing of personal protective equipment (powered, air-purifying respiratory). Based on our experience and aligned with other groups, ${ }^{2}$ we strongly recommend simulation when devising a COVID-19 tracheostomy protocol (Figure 1).

\section{SPECIAL CONSIDERATIONS FOR \\ TRACHEOSTOMY IN PATIENTS WITH COVID-19}

A dedicated multidisciplinary team evaluates the patient and employs a standardized pretracheostomy checklist (Table 2). As there is no current evidence to suggest early tracheostomy ( $<7$ days) or delayed tracheostomy ( $>2-3$ weeks) is of particular benefit in this population, we consider tracheostomy a minimum of 7 days after

TABLE 2. Pretracheostomy checklist for patients with COVID-19

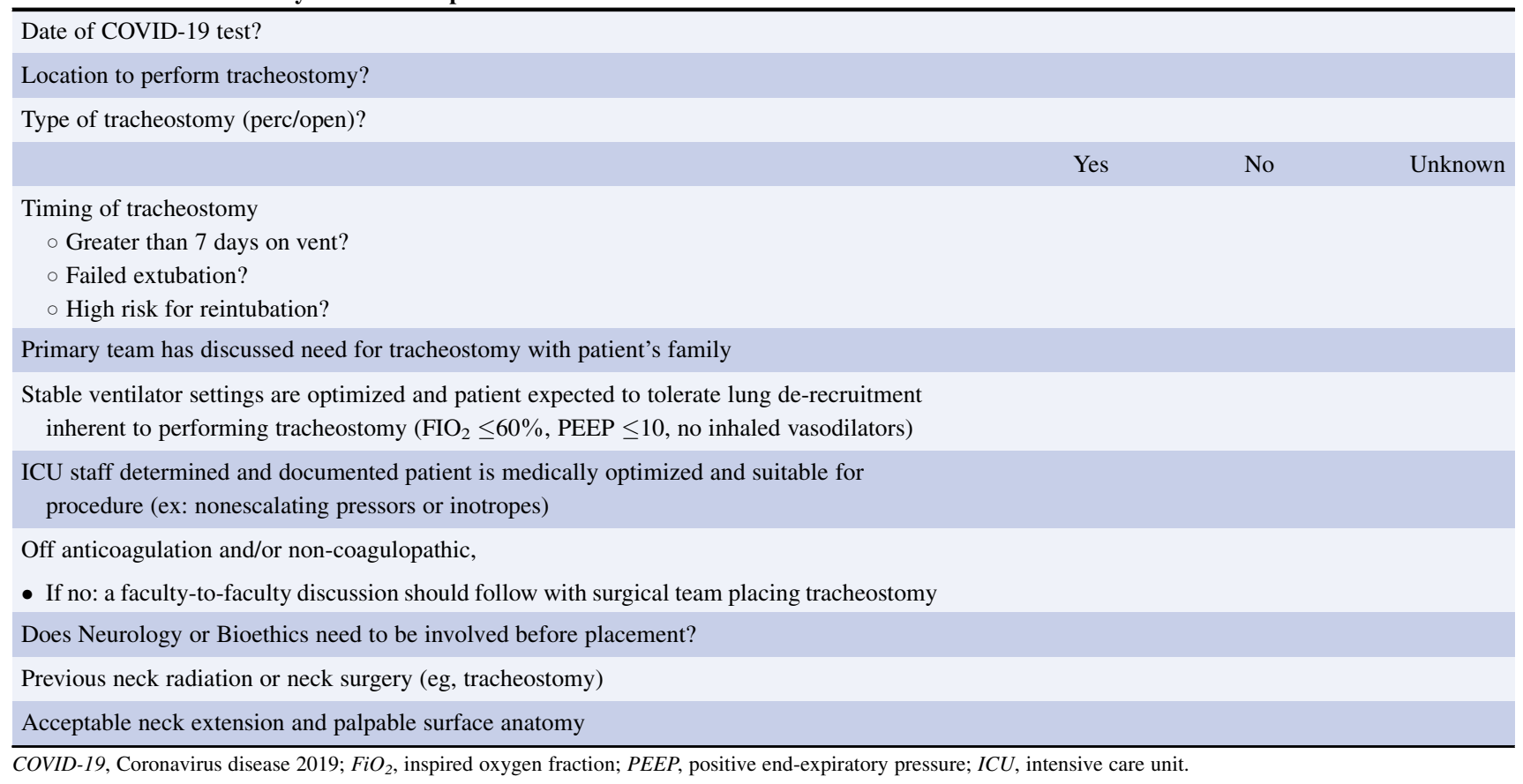


TABLE 3. Step-by-step approach to percutaneous tracheostomy in patients with COVID-19

\section{HCW involved}

Inside room: 2-3 $\mathrm{HCW}$ (to be limited as much as possible)

Bronchoscopy/airway: staff provider (thoracic surgery, IP, ICU, or ENT)

Operator/tracheostomy insertion: staff provider (thoracic surgery, IP, or ENT)

Outside room: as needed

ICU respiratory therapist (ventilator located outside room)

- Assist with ventilator including period of apnea

Bedside/ICU RN (IV pumps outside room)

- Administer ordered/prescribed sedation and paralytics

- Adjust vasoactive drips as necessary and/or directed

Intensivist

- Ready to don PPE and enter for assistance if required

- Additional airway provider

- Additional medications for sedation, paralysis and hemodynamic support

***Team members must coordinate on key signs to convey the following (since verbal communication limited with PAPRs and 2 members will be inside room)

- Ventilator on (thumbs up)

- Ventilator off (thumbs down)

- Need for additional help (wave in)

Key steps of bedside percutaneous tracheostomy

1. Patient deeply sedated and paralyzed for procedure

- Recommend initiating sedation process (under direction of intensivist) before tracheostomy team entering room

- Ensure deep sedation before administrating paralysis

- Administer paralysis at least 3-5 min before insertion of bronchoscope to allow effect

2. Preoxygenate with $100 \% \mathrm{FiO}_{2}$ for a minimum of $3 \mathrm{~min}$

3. Preparation of equipment outside room

- Tracheostomy tray under sterile condition outside the patient's room

- Bronchoscopy cart with disposable bronchoscope, ensure proper functioning

- Shoulder roll for neck extension

4. Don PPE: (1) PAPRs if available or N95 (not both); (2) full face shield/visor; (3) hair covers, shoe covers; (4) disposable gown; and (5) double gloving

5. Both operator and bronchoscopist enter room

6. Preparation inside room

- Operator scrubs in and preps and drapes area

- Bronchoscopist positions patient neck in optimally in extension with roll support and packs oropharynx with moist Kerlix roll (not gauze squares to avoid retention)

7. Visualized ETT withdrawal using controlled deflation of cuff over bronchoscope to subglottic position

- Removal of minimal amount of air from cuff may likely be required to withdraw ETT to level needed for appropriate visualization

(Continued)
TABLE 3. Continued

Key steps of bedside percutaneous tracheostomy

8. Communication through visual cue that ventilation needs to be paused/apnea time starts

9. Insertion of angiocatheter once first tracheal ring identified

- Insertion between first and second or second and third tracheal rings

- Serial dilation (moist gauze available on field to cover neck stoma as needed)

- Insertion of tracheostomy

10. With tracheostomy in place $\rightarrow$ immediately insert bronchoscopy into tracheostomy for confirmation that tip is above carina and no significant bleeding

11. Remove bronchoscope from tracheostomy $\rightarrow$ immediately connect HME + in-line suctioning to tracheostomy

12. Connect to ventilator. Hand signal to start ventilation

- Estimated apnea time $<1 \mathrm{~min}$

13. After satisfied no issues with procedure $\rightarrow$ remove endotracheal tube and place immediately into biohazard bag

14. Secure tracheostomy with sutures and strap per routine

15. Proper doffing of PPE before existing

$H C W$, Health care worker; $I P$, interventional pulmonology; $I C U$, intensive care unit $E N T$, ear, nose, and throat; $R N$, registered nurse; $I V$, intravenous; $P P E$, personal protective equipment; $P A P R s$, powered, air-purifying respiratory; $\mathrm{FiO}_{2}$, inspired oxygen fraction; ETT, endotracheal tub; $H M E$, heat and moisture exchanger.

intubation and preferably after 10 to 14 days to enter the convalescent phase of the disease, gain the benefits of the procedure, and permit time for prognostication of overall recovery. We do not advocate waiting until a repeat negative COVID-19 test, as this could unnecessarily prolong time to tracheostomy, given possibility of persistently positive test (one series ${ }^{3}$ with median 20 days, longest 37 days), which likely represents continued noninfectious viral shedding. ${ }^{4}$ In addition, we always advocate for maximum available personal protective equipment regardless of a negative COVID-19 tests to protect health care workers (HCWs).

\section{OUR APPROACH TO TRACHEOSTOMY IN PATIENTS WITH COVID-19 Location and Tracheostomy Approach}

Our default location is bedside in intensive care unit (ICU) to minimize patient transport and exposure risk, with the operating room used for particularly high-risk cases. For bedside tracheostomies, an enclosed negativepressure ICU room is preferred if available and logistically feasible. Our team favors percutaneous over the open technique with deference to operator preference and patient anatomy. 


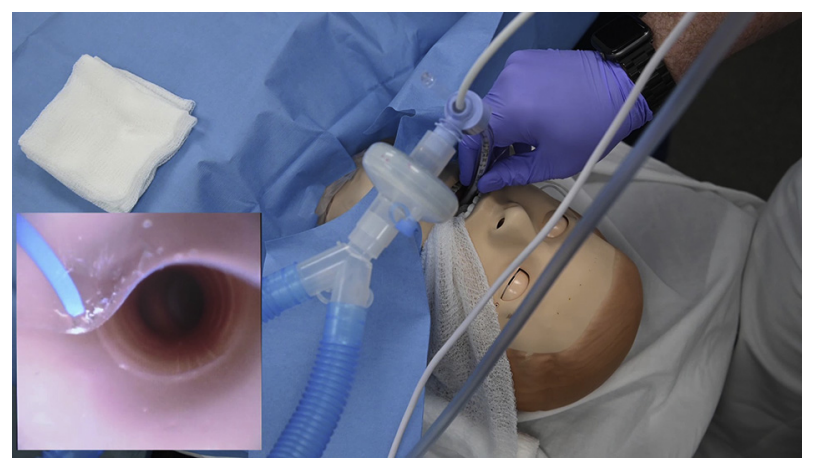

VIDEO 1. COVID-19 tracheostomy simulation. Narrated and annotated video demonstrating our step-by-step approach to performing percutaneous tracheostomy in patients with COVD-19 using a high-fidelity simulation model. (Length of movie: 9 minutes, 9 seconds.) Video available at: https://www.jtcvs.org/article/S2666-2507(20)30718-5/fulltext.

\section{Tracheotomy Details}

The type of tracheostomy appliance is largely based on the institutional preference and available supply. Our group favors an appliance without inner cannula to mitigate exposure risk of inner cannula exchange. Step-by-step details of the tracheostomy procedure with modifications to minimize aerosolization are listed in Table 3 and depicted in Video 1.
In patients with COVID-19, we arrange all ventilator control and intravenous lines outside the room so care can be delivered without repeatedly entering the space. The sterile tracheostomy tray is prepared out of the enclosed room.

A moist Kerlix roll is packed in the oropharynx to minimize aerosolization as the endotracheal tube is withdrawn into the subglottis. This obviates the need for a protective box/tent. A disposable bronchoscope is used to avoid exposure during cleaning and processing of a soiled bronchoscope.

The endotracheal tube is pulled back with cuff inflated into the subglottic position. Further retraction can be facilitated by removing the minimal necessary amount of air from the cuff. After guidewire insertion, we perform the remainder of the procedure under apnea and attempt to limit procedural time to 60 to 90 seconds.

\section{CONCLUSIONS}

Performing tracheostomy in the COVID-19 era exemplifies how a previously straightforward clinical decision for an essential-elective procedure has been reimagined when the safety of more than just the patient must be considered. The balance of anticipated benefits and risks for major stakeholders (patient, health care system, and $\mathrm{HCW}$ ) will vary between different locations during various stages of the COVID-19 pandemic as evidenced by a

TABLE 4. Select COVID-19 tracheostomy guidelines

\begin{tabular}{|c|c|c|c|c|c|}
\hline $\begin{array}{c}\text { Author location/group } \\
\text { date published }\end{array}$ & Timing of trach & COVID neg before? & Approach & PPE & Location \\
\hline $\begin{array}{l}\text { NTSP }^{6} \\
\text { UK } \\
\text { March } 2020\end{array}$ & $\begin{array}{l}\text { Until COVD-negative/ } \\
\text { noninfectious or } \\
\text { At least } 14 \mathrm{~d}\end{array}$ & ND & Either & PAPR & $\mathrm{ICU}$ \\
\hline $\begin{array}{l}\text { University } \\
\quad \text { of Michigan } \\
\text { April } 2020\end{array}$ & $\begin{array}{l}\text { Until absolutely } \\
\text { necessary }\end{array}$ & $\begin{array}{l}\text { Neg } \times 2,24 \mathrm{~h} \text { apart and } \\
\text { Resolution of fevers }\end{array}$ & Either & PAPR/N95 & ICU \\
\hline $\begin{array}{l}\text { Takhar }^{8} \\
\text { London/UK } \\
\text { April } 2020\end{array}$ & $14 \mathrm{~d}$ & $\begin{array}{l}\text { If testing available and } \\
\text { considering before } 14 \mathrm{~d}\end{array}$ & PDT > Open & PAPR & $\begin{array}{l}\text { Negative-pressure } \\
\text { rooms; ICU }\end{array}$ \\
\hline $\begin{array}{l}\text { Tao }^{9} \\
\text { UPenn } \\
\text { April } 2020\end{array}$ & $21 \mathrm{~d}$ & ND & Open $>$ PDT & PAPR & $\begin{array}{l}\text { ICU, negative } \\
\text { pressure }>\text { OR }\end{array}$ \\
\hline $\begin{array}{l}\text { Pichi }^{10} \\
\text { Italy } \\
\text { April } 2020\end{array}$ & $\begin{array}{l}\text { (7 d) Mentioned, not } \\
\text { formally recommended }\end{array}$ & ND & Open & N95 & $\mathrm{OR}>\mathrm{ICU}$ \\
\hline $\begin{array}{l}\text { Michetti, }{ }^{11} \text { AAST } \\
\text { April } 2020\end{array}$ & $\begin{array}{l}\text { Until viral shedding } \\
\text { ceased }\end{array}$ & $\begin{array}{l}\text { Recommend against trach } \\
\text { with active disease - } \\
\text { confirm } \\
\text { nontransmissibility }\end{array}$ & Either & PAPR + N95 & ND \\
\hline $\begin{array}{l}\text { Lamb }^{12} \\
\text { CHEST } \\
\text { June } 2020\end{array}$ & $\begin{array}{l}\text { Insufficient evidence to } \\
\text { recommend timing }\end{array}$ & $\begin{array}{l}\text { Do not recommend routine } \\
\text { RT-PCR testing prior to } \\
\text { trach }\end{array}$ & Either & Enhanced PPE & $\begin{array}{l}\text { Neg pressure room; } \\
\quad \text { ICU }>\text { OR }\end{array}$ \\
\hline
\end{tabular}


multitude of available guidelines ${ }^{5}$ (Table 4). A multidisciplinary team is essential in developing a center-specific protocol for COVID-19 tracheostomy with an indispensable role for simulation and team rehearsal. This activity allows providers who may not have previously worked together to pool shared experience and knowledge to develop a tailored, efficient, and safe protocol. Following this protocol, our team has performed more than 20 percutaneous tracheostomies (including 4 patients on extracorporeal membrane oxygenation) in the ICU without untoward patient events or evidence of COVID-19 transmission to HCWs. It is through synergistic collaboration that the optimal delivery of health care can be safely achieved during this continued pandemic.

\section{References}

1. Wu Z, McGoogan JM. Characteristics of and important lessons from the coronavirus disease 2019 (COVID-19) outbreak in China: summary of a report of 72314 cases from the Chinese center for disease control and prevention. JAMA. 2020; 323:1239-42

2. LoSavio PS, Eggerstedt M, Tajudeen BA, Papagiannopoulos P, Revenaugh PC, Batra PS, et al. Rapid implementation of COVID-19 tracheostomy simulation training to increase surgeon safety and confidence. Am J Otolaryngol. 2020; 41:102574.

3. Zhou F, Yu T, Du R, Fan G, Liu Y, Liu Z, et al. Clinical course and risk factors for mortality of adult inpatients with COVID-19 in Wuhan, China: a retrospective cohort study. Lancet. 2020;395:1054-62.
4. Sethuraman N, Jeremiah SS, Ryo A. Interpreting diagnostic tests for SARS-CoV2. JAMA. 2020;323:2249-51.

5. Chiesa-Estomba CM, Lechien JR, Calvo-Henríquez C, Fakhry N, Karkos PD, Peer S, et al. Systematic review of international guidelines for tracheostomy in COVID-19 patients. Oral Oncol. 2020;108:104844.

6. National Tracheostomy Safety Project. NTSP Considerations for tracheostomy in the COVID-19 outbreak. Available at: https://www.tracheostomy.org.uk/ storage/files/NTSP $\% 20$ Advice $\% 20$ for $\%$ 20patients $\% 20$ with $\% 20 a \% 20$ tracheo stomy $\% 20$ in $\% 20$ the $\% 20$ Coronavirus $\% 20$ pandemic.pdf. Accessed May 1, 2020 .

7. Michigan Medicine Tracheostomy Working Group. Michigan medicine tracheostomy guidelines in COVID-19 era. Available at: http://www.med.umich.edu/ surgery/mccen/documents/MM-Guidelines-for-Tracheostomy-in-COVID19era.pdf. Accessed May 1, 2020.

8. Takhar A, Walker A, Tricklebank S, Wyncoll D, Hart N, Jacob T, et al. Recommendation of a practical guideline for safe tracheostomy during COVID-19 pandemic. Eur Arch Otorhinolaryngol. 2020;277: 2173-84.

9. Chao TN, Braslow BM, Martin ND, Chalian AA, Atkins J, Haas AR, et al. Tracheostomy in ventilated patients with COVID-19. Ann Surg. 2020;272:e30-2.

10. Pichi B, Mazzola F, Bonsembiante A, Petruzzi G, Zocchi J, Moretto S, et al CORONA-steps for tracheotomy in COVID-19 patients: a staff-safe method for airway management. Oral Oncol. 2020;105:104682.

11. Michetti CP, Burlew CC, Bulger EM, Davis KA, Spain DA. Performing tracheostomy during the Covid-19 pandemic: guidance and recommendations from the Critical Care and Acute Care Surgery Committees of the American Association for the Surgery of Trauma. Trauma Surg Acute Care Open. 2020;5: $\mathrm{e} 000482$.

12. Lamb CR, Desai NR, Angel L, Chaddha U, Sachdeva A, Sethi S, et al. Use of tracheostomy during the COVID-19 pandemic: American College of Chest Physicians/American Association for Bronchology and Interventional Pulmonology/ Association of Interventional Pulmonology Program Directors Expert Panel Report. Chest. 2020;158:1499-514. 